\title{
Mobile Application for Vision Impaired People to Facilitate to Learn the English Language
}

\author{
Anuradha Jayakody \\ Senior Lecturer, Sri Lanka \\ Institute of Information \\ Technology \\ Malabe, Sri Lanka \\ G.T.S. Silva \\ Software Engineer \\ Sri Lanka Institute of \\ Information Technology \\ Malabe, Sri Lanka
}

\author{
Shashika Lokuliyana \\ Lecturer \\ Sri Lanka Institute of \\ Information Technology \\ Malabe, Sri Lanka
}

\author{
S.A.L. Rajanthika \\ Software Engineer \\ Sri Lanka Institute of \\ Information Technology \\ Malabe, Sri Lanka
}

\author{
A.A.T. Sampath \\ Software Engineer \\ Sri Lanka Institute of \\ Information Technology \\ Malabe, Sri Lanka
H.M.T.B. Seneviratne
Software Engineer
Sri Lanka Institute of
Information Technology
Malabe, Sri Lanka

\begin{abstract}
This paper brings together the development of a mobile application which capable of providing English language guide for vision impaired people. This research work has proposed and implementation of a system called "An English Eye: Way to Learn English as a Vision Impaired Individual" to facilitate blind people to learn English as a secondary language using mobile based application which is capable of translating an English word into its corresponding Sinhala word and vice versa. The system consists of the speech recognizer, translators, a speech synthesizer, gesture interactions and latest technologies that have been applied to make it more accessible for vision-impaired people. Also, to the translator, this system comes with features such as brail input methodologies, character segmentation techniques, speech to text conversation, and so forth. English is a lingua franca which is critical to tertiary education through a substantial amount of learning and teaching materials are available in English. Many academics and researchers have proposed different methodologies to learn English using existing technologies; i.e. educational software, CDs, DVDs, videos, e-mails, internet. Though there are resources, it is still a challenge to learn English as a vision impaired student in the Sri Lankan context due to lack of accessibility issues engaged with resources mentioned above. In addressing this needs, the challenge of building a mobile application to help vision impaired people was taken up.
\end{abstract}

\section{General Terms}

English Eye, Vision impaired English Learning

\section{Keywords}

English Eye, Vision Impaired Learning, Braille interface

\section{INTRODUCTION}

As a community, English is not a mother tongue, but most of the people in the world use it as a linking language. Therefore, when it comes to vision impaired context, due to lack of learning resource, it becomes a challenge for them.

\subsection{Problem}

According to the survey conducted by the authors at the Ceylon School for Deaf \& Blind, and the Employers Federation of Ceylon identifies that vision impaired individuals have difficulty learn The English language.
Hence, they are facing difficulties in grasping employment opportunities such as Help Desk Assistance, Operator, Reception.

\subsection{Solution}

English Eye is a solution, to assist the vision impaired people in overcoming the challenge of learning The English language. It is a smart mobile device based application, which they can use for themselves to learn and improve their English knowledge. The person who is using the application has the freedom of using gestures or reasonable approach to controlling and navigate through the application. The application provides a range of lectures, tests, evaluations and feedbacks for the user to assist and improve their English language knowledge.

As an interface, the system may provide a brail keyboard for inserting text as they are familiar, so it facilitates to read and write as they trained. Further, the application would support to get the feedback both voice or as a printed sheet. The embed dictionary has both voice and braille input.Further, it supports Sinhala and English language vice versa. The lesson practice and sentence builder work with a grammar checker, and it provides more supports to the individual vision impaired beginner.

\subsection{English Eye and Existing Applications}

The Table 1.3.1 presents a comparison of other applications and their functions, accuracy, etc. Also, what functionality available with the proposed product, and how it varies from existing application and other products. 
Table 1.3-1 Basic Comparison with existing products

\begin{tabular}{|c|c|c|c|c|c|c|}
\hline $\begin{array}{l}\text { प्ّ } \\
\text { हू } \\
\text { 品 }\end{array}$ & 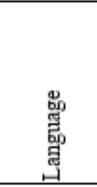 & $\begin{array}{l}\text { 总 } \\
\text { 总 } \\
\text { 穿 }\end{array}$ & 总 & 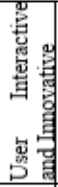 & 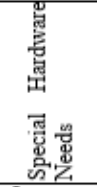 & 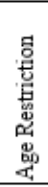 \\
\hline $\begin{array}{l}\text { Ellvis } \\
\text { English } \\
\text { Course }\end{array}$ & $\begin{array}{l}\text { English } \\
\text { French, } \\
\text { German, } \\
\text { Romania }\end{array}$ & Standalone & Free & yes & $\begin{array}{l}\text { Joy } \\
\text { Stick, } \\
\text { 3D } \\
\text { surround } \\
\text { sound } \\
\text { card }\end{array}$ & $\begin{array}{l}20- \\
50\end{array}$ \\
\hline $\begin{array}{l}\text { Smarter } \\
\text { Balance } \\
\text { Testing and } \\
\text { Students } \\
\text { with Visual } \\
\text { Impairment }\end{array}$ & English & Online & $\begin{array}{l}\text { Free for } \\
\text { Academic } \\
\text { Institute } \\
\text { only }\end{array}$ & No & No & $\begin{array}{l}\text { 18- } \\
\text { Jun }\end{array}$ \\
\hline $\begin{array}{l}\text { Listening } \\
\text { Guidelines } \\
\text { for English } \\
\text { Language } \\
\text { Learners } \\
\text { By ABF }\end{array}$ & English & Online & $\$ 49$ & No & No & No \\
\hline $\begin{array}{l}\text { English } \\
\text { Eye }\end{array}$ & $\begin{array}{l}\text { English, } \\
\text { Sinhala }\end{array}$ & $\begin{array}{l}\text { Mobile } \\
\text { Application }\end{array}$ & $\begin{array}{l}\text { Yet to be } \\
\text { Decide }\end{array}$ & Yes & No & No \\
\hline
\end{tabular}

The major method for blind learners is DVD and electronic media that includes lessons and exams with voice recorded lessons and exams. Those lessons continued about one hour or more, so vision impaired student in a lazy mood and lost their concentration to the lesson.

Other existing application builds with English language and needs special hardware devices that with a high cost. These factors not acceptable in Sri Lankan context because still considered as a developing country.

To overcome above mentioned issues build a smartphone based mobile application with many interactive ways that tend blind user to keep in touch with the learning process. Below the table 1.3.2 describe main functionalities of the proposed application.

Table 1.3-2 Comparison with functionalities

\begin{tabular}{|l|l|l|l|l|l|}
\hline \multicolumn{2}{|l|}{ Product } & $\begin{array}{l}\text { Braille } \\
\text { Print }\end{array}$ & DVD & Ellvis & $\begin{array}{l}\text { English } \\
\text { Eyel }\end{array}$ \\
\hline 1 & Interactive & X & X & $\checkmark$ & $\checkmark$ \\
\hline 2 & Available Exams & $\checkmark$ & $\checkmark$ & $\checkmark$ & $\checkmark$ \\
\hline 3 & Touch options & $\mathbf{x}$ & $\mathbf{x}$ & $\mathbf{x}$ & $\checkmark$ \\
\hline 4 & Voice recognition & $\mathbf{x}$ & $\mathbf{x}$ & $\mathbf{x}$ & $\checkmark$ \\
\hline 5 & Low Cost & $\checkmark$ & $\mathbf{x}$ & $\mathbf{x}$ & $\checkmark$ \\
\hline 6 & Spell checker & $\mathbf{x}$ & $\mathbf{x}$ & $\mathbf{x}$ & $\checkmark$ \\
\hline 7 & Gesture patterns & $\mathbf{x}$ & $\mathbf{x}$ & $\mathbf{x}$ & $\checkmark$ \\
\hline 8 & Chat Bot (Counselor) & $\mathbf{x}$ & $\mathbf{x}$ & $\mathbf{x}$ & $\checkmark$ \\
\hline 9 & Lessons & $\checkmark$ & $\checkmark$ & $\checkmark$ & $\checkmark$ \\
\hline 10 & Dictionary & $\checkmark$ & $\mathbf{x}$ & $\mathbf{x}$ & $\checkmark$ \\
\hline
\end{tabular}

\section{METHODOLOGY}

The system specially designed for the vision-impaired learner who is unable to use available resources to a sighted individual. This system developed, considering blind students all the functions and features overcome an accessibility issued they have faced throughout their life. Hence, this research work considers facilitating with an application for vision impaired people in Sri Lanka,

There are many products and apps are available within the country for sighted people to learn English that rarely localize for Sinhalese peoples. Though, there is also applications available for vision impaired people for their day to day life activities and indoor and outdoor navigation system that localize in the Sinhala language. According to the requirement gathered within the country, it has identified they are familiar with Braille keyboard when they are using computers. Hence, this application consists standard, gesture and voice recognition technologies and algorithms to facilitate both sited and vision impaired individuals. As a unique feature, the system has double tap to open, select, start and clear option within the application to provide accessibility facility to operate the interfaces without others interaction. Additionally, users can select standard or gesture mode.

This application includes several packages (subcomponent) for improving English knowledge. All the packages built in the Sinhala language for better localization. The Sinhala, to English dictionary, includes Sinhala text to Sinhala voice engine, for providing the definitions of searched word with the Sinhala voice output. In word input and answer input process are a modification of the English language braille touch methodology. Therefore blind user does not want an appropriate training for using the Braille touch input method. There are voice based English grammar lesson and spoken English lessons. While listening to the experiences questions are asking for it provides a special feature to make users keep their attention on learning the process and better motivation. In the spoken English learning process, there is an artificially intelligent talking application specially designed for Sri Lankan blind peoples for self-practice. To have a better idea about knowledge level and success of learning process, the user can use evaluation process specially designed with series of exams.

According to the findings, only a few products are available in the local and international market, and they consist only listing facility to learn English. Further, it needs addition devices such as joysticks and separate brail keyboards. According to the testing and evaluation end-users satisfied compared existing devices.

This product mainly focuses Sri Lankan vision impaired students without age restriction that eager to improve their English language knowledge. It has accessible features to identify the needs and aspirations of vision impaired persons and to provide a better educational method to achieving their goals. In this work design developed a mobile application which will enable the vision-impaired people to learn The English language easily without others interaction. This application mainly based on gesture patterns and touch movements, so that vision impaired can use it in a more accessible way compared to existing products.

As an added advantage sighted people will also be able to use this application in normal mode and zooming capabilities are available for people who are partially blind.

The user will be able to input text input using the braille touch system to implement in our system. There will be a Sinhala braille touch system also for inputting Sinhala text.

There are five sub-components available for users, namely 
1. English alphabet learning process

2. Sinhala, English dictionary

3. Spoken English learning process

4. English grammar learning process

5. Evaluation Process

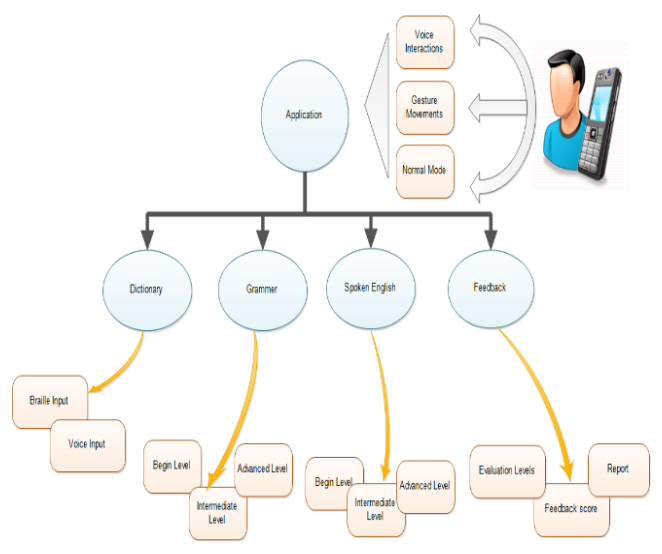

Figure 2-1 System Overview

All of these functions available in Sinhala knowledge with Sinhala guidelines. Advanced level English grammar lessons and spoken English lessons guide with simple English for better usage in English.

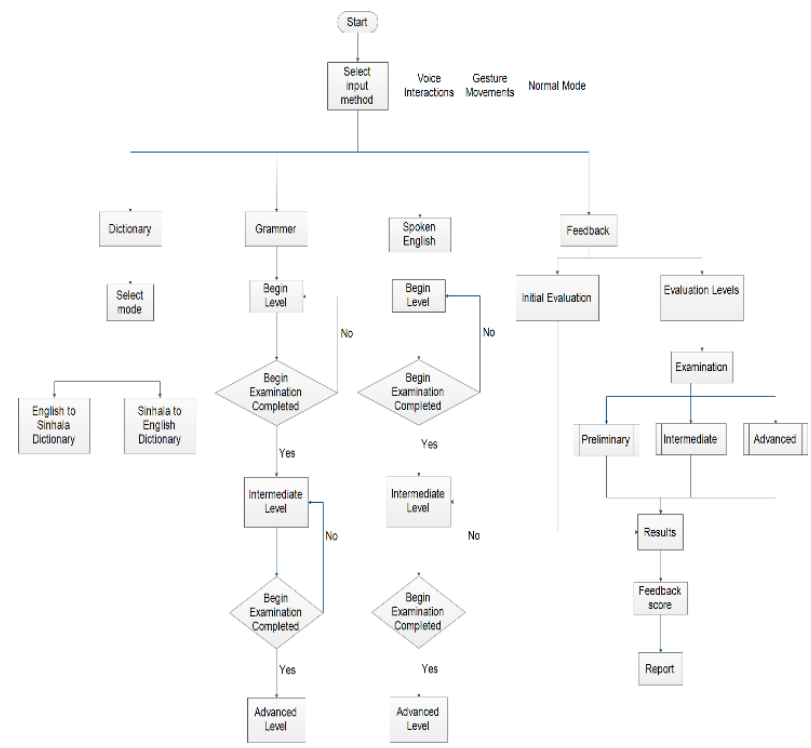

Figure 2-1 Flow chart of the application

English Alphabet component content change according to selected mode. If the user selects normal mode, guideline and examples will be given for normal English alphabet. If the user selects gesture mode, directives and examples will be given for learning braille English alphabet.

The Sinhala, English component includes three dictionary models,

1. English to English dictionary

2. English to Sinhala dictionary

3. Sinhala to English dictionary
English to Sinhala dictionary includes Sinhala text to Sinhala voice engine for giving the meaning of relevant English word in Sinhala voice for blind users.

There are many ways to learn English grammar in the modern social club. There is some application that can be utilized for improving grammar knowledge for regular users. Even though many apps available it is very rare and hard to recover an application with high quality and especially build for Sri Lankan blind people for improving the use of grammar knowledge.

The grammar learning process includes three levels,

1. Beginner Level

2. Intermediate Level

3. Advanced Level

If the user cannot decide his/her knowledge level, User can attempt for an initial exam and get a better idea of knowledge level. Every level content series of grammar lessons and Examination relevant for that lesson.

When the user is listening to the teachings, it takes some time while user listening to that lessons user may get boarded or user misses the concentrate to that lessons. When learning focus to that lesson is a most important thing. Therefore to make user concentrate our application provide the distinctive feature.

When the user is listening, it will check the user is listening to the lesson by asking to draw a gesture pattern or press a button. This process specially designs for according to the vision impaired people.

When listening to the lesson application generate accidental time periods according to the dimension of the lesson. Then application asks to draw or select random gesture arrangements to check the user attentiveness level. If the user selects the correct random gesture pattern application to reduce the random gesture pattern actions and after some period again, it may checked the user attention. Therefore, the application can keep track of user without any other conflict.

Following figures display the gesture patterns that application will generate to measure the user attentiveness. 


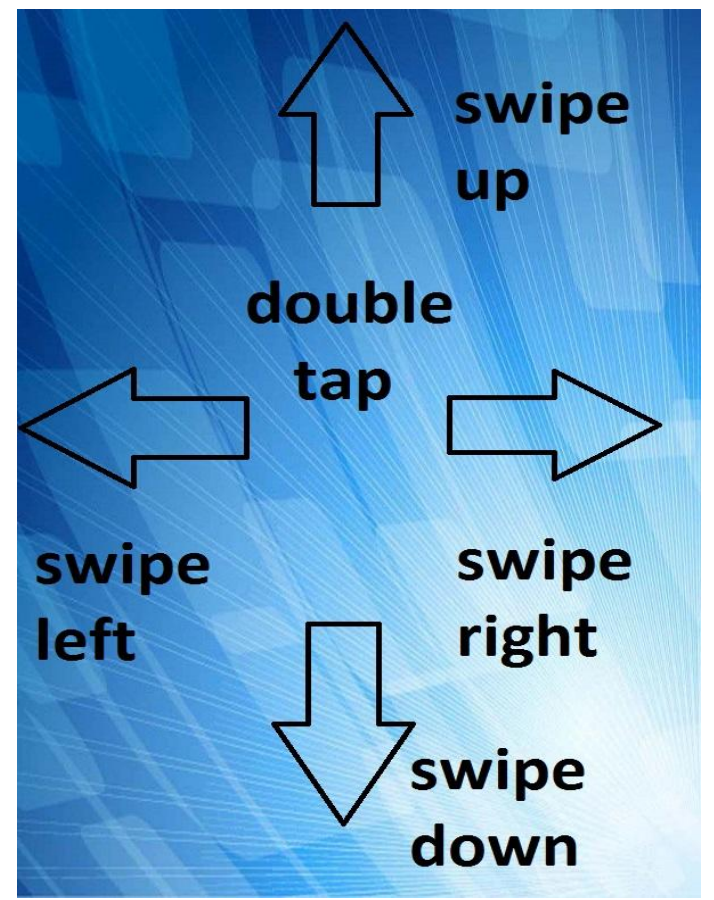

Figure 2-2 Gesture Pattern Example

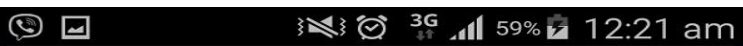

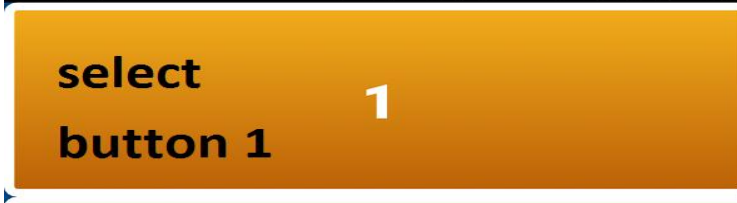

\section{select} button 2

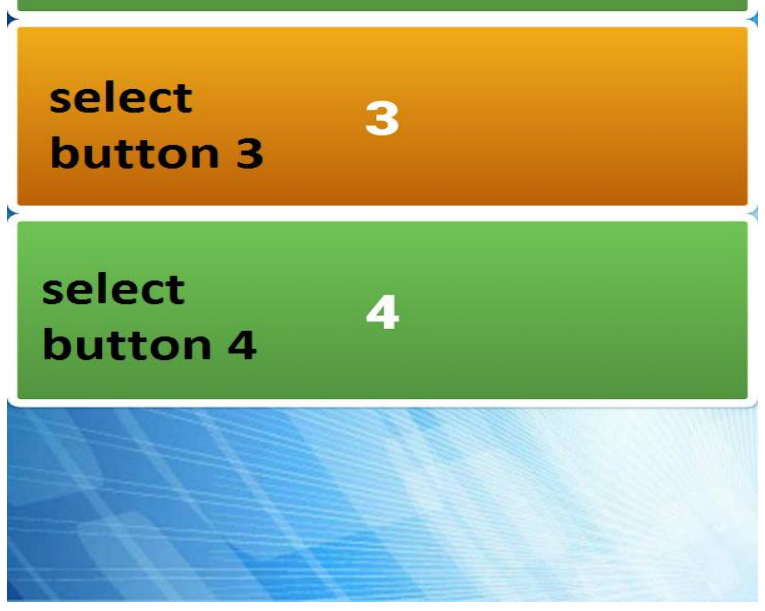

Figure 2-3 Button Selection Example

The spoken English learning process includes several subfunctions,
1. Spoken English lessons
2. Spoken English Conversations
3. Sentence Builder
4. Self-practice

Spoken English lesson content categories as a beginner, intermediate and advanced level as before the mention of the grammar learning process. Questions during the lesson also checked the user to concentrate on facilitating better in the learning process. Conversations are also categories for three levels, as a beginner, intermediate and advanced level. These conversations can here line by line or as a full conversation in slow speed and normal speed. Explanation of the each and every conversation will available for users' better understand. Sentence Builder can be used to build sentences in 3 sentence type, namely simple, compound and complex. In this function, the user can make the sentence, choosing words and it will be translated in The English language.

Self-practice function includes an artificially intelligent chat bot localize for Sri Lanka and specialize for vision impaired people. The user can have a conversation with the chat, but anytime and practice spoken English in innovative ways. Voice input will also accept in this chat function.

Evaluation and feedback process contain with series of the exam to check grammar knowledge and Spoken English knowledge. The initial exam can be used to check knowledge level and used those results to select what level user needs to start the learning process.

English language learning process begins at the beginner level. Hence, any blind user will be able to learn English using this application. The lesson series is developed according to the self-access language learning course. This application focuses on achieving reading, speaking and writing. The app features includes as following:

1. Speech to text conversion [3]

This feature will be used when giving a voice command to the application via microphone. In this process given input speech will convert to text output and it will be used for further processing.

2. Sinhala text to Sinhala voice conversion

Sinhala and English dictionary use this feature when user input an English word and the meaning of appropriate English word display in Sinhala text. Blind users cannot see the text content on the screen so Sinhala text should read aloud in the Sinhala language.

3. Resume Interactions

Managing interactions with other applications. For instance, if call occurred during the learning process going on, it can start to form the point that call was received.

4. Character segmentation.

This feature will be used in when the user is giving an answer to the lessons. To process the word, first of all, it needs to separate the words and check the character. Then the user can use those characters in the process.

\section{Disable Options}

When a user interacts with the system unwanted keys will disable for a blind user to easily interact with the system. Use the special command to directly enable the features and keys.

6. Braille input methodology

When inserting word or answer to the blind application user can use braille input method.

7. Spell checking option

Check user's pronunciation using words phoneme representation. Use a special algorithm to build phoneme representation of given word. 


\section{RESULTS AND DISCUSSION}

Currently application test and developed as a mobile application based on Android tablets and phones. Took feedback from the mobile application and did the further development process by arranging regular meetings with blind students at Employers Federations of Ceylon. Using feedback did the modification to assure the quality of the lesson and give more accessible facility for blind pupils in the application, and it is guaranteed that the application fulfilled of blind people user requirement.

\subsection{Testing Results}

Testing is the one of the most important facets of the software development life cycle. There are various stages at which testing is done to ensure the quality of delivery.

Task 1(T1): User needs to go to the first selection of spoken English lesson one.

Method 1(M1): Voice navigation. The system gets user inputs as voice commands.

Method 2(M2): Drawing gesture patterns. The system gets user input as gesture patterns. As an example when the user wants to go back from the current screen system asks to draw No. 1 on the screen.

Method 3(M3): Button navigation system similar to the Google talkback navigation. The system gives vibration feedback and lets's know what's on the screen, what user is touching \& what can do with it.

S1, S2, S3, S4 \& S5 are the average times for the samples of vision impaired person who has tested the Task1 using above three methods.

S1, S2, S3, S4 \& S5 are the student groups which consist of five students for each.

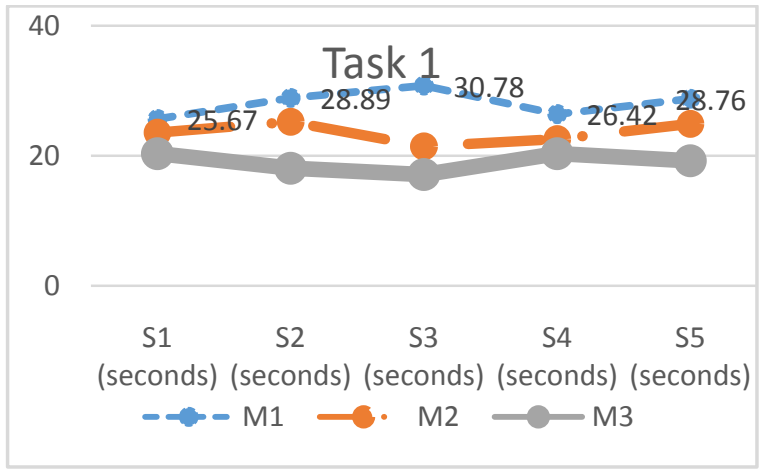

Figure 3.1-1 Task 01 Graph

In development progress to concentration user when user lesson to the lessons ,hence implement several mechanisms. One feature is asked questions in the middle of the lessons. The user needs to give voice input for the application. Because of the different assets of users, it is unable to continue with the lessons. Next mechanism is when the application asks to draw an one gesture pattern it not very accurate because user tries always to know what to do when the application asks about concentration check event. Therefore final we come up with different gesture patterns and button presses with random time periods which change according to the concentration user level. This mechanism provides high accuracy level compared to other techniques that we have tested.

\section{CONCLUSION}

Blind and partially sighted people face difficulties to learn The English language due to inaccessibility of the printed materials because they required braille device. In Sri Lanka when considering the braille English learning resources are lacking for vision impaired users. As a developing country; unable to fill their requirements because due to high cost. As a solution this mobile application designed according to the useful navigations techniques using gesture and voice interactions. Therefore, the blind and partially sighted people can access the system effectively and efficiently.

As well as a system designed for blind people and partially sighted people. Hence, it covers all the range of vision impaired disability persons.

In addition to, it can be used for normal users who are interested in English language but also can think about international market as well.

\section{ACKNOWLEDGMENTS}

This work has supported by Sri Lanka Institute of Information Technology, Malabe, Sri Lanka.

The authors appreciate the guidance provided by Ms. H.K. Manique Gunaratne of the Employer's Federation of Ceylon and all other members of the blind student training center who has provided the necessary advice and support for the research.

\section{REFERENCES}

[1] Ceylon school of deaf and blind," Blind School",[Online].Available:www.csdeafblind.lk/blind_sc hool.php

[2] The Employers Federation of Ceylon, "EPC Network on Disability", [Online].Available: www.employers.lk/services/etc-network-on-disability

[3] B.Raghavendhar.Reddy, E.Mahender, "Speech to Text Conversion using Android Platform",[Online].Available:www.ijera.com/papers/Vol 3_issue1/AJ31253258.pdf

[4] Verena Stein, Robert Neßelrath and Jan Alexandersson, "Improving Spelling Skills For Blind Language Learners" in German Research Center for Artificial Intelligence - DFKI GmbH, Saarbr"ucken, Germany

[5] Buxton, W., Hill, R., and Rowley, P.” Issues and techniques in touch-sensitive tablet input" in SIGGRAPH '85, 215-224

[6] Shaun K. Kane1,6, Meredith Ringel Morris2, Annuska Z. Perkins3, Daniel Wigdor4, Richard E. Ladner5, Jacob O. Wobbrock6 "Improving Non-Visual Access to Large Touch Screens for Blind Users" in Computer Science \& Engineering 6 Information School | DUB Group University of Toronto University of Washington

[7] Shaun K. Kane1, Meredith Ringel Morris, Annuska Z. Perkins, Daniel Wigdor, Richard E. Ladner ,Jacob O. Wobbrock "Access Overlays: Improving Non-Visual Access to Large Touch Screens for Blind Users" in Computer Science \& Engineering , Information School | DUB Group University of Toronto University of Washington University of Washington Toronto, On Canada Seattle, WA 98195 USA 16, 10 (2011).

[8] Thomas Deharde, Accessible Language Learning for Vision Impaired People, [online]: 
Available:http://conference.pixelonline.net/ICT4LL2010/ common/download/Proceedings_pdf/IBL55-Deharde.pdf

[9] National Center for Education, Smarter Balanced Assessment Consortium, [Online]: Available:http://www.smarterbalanced.org/wordpress/wp content/uploads/2014/08/SmarterBalanced_Guidelines.p df

[10] AFB staff, Listening Guidelines for English Language Learners [online]: Available: http://www.afb.org/blog/afb-blog/listening-guidelinesfor-english-language-learners/12
[11] Dr. Serge Resnikoff, Prevention of Blindness and Deafness Program [online]: Available: http://www.who.int/mediacentre/news/releases/2003/pr7 $3 / \mathrm{en} /$

[12] W.A.P.Binosha Shirazi, U.P Dickwella, G.CPeiris, .M.B.S.CIllangasinghe, Anuradha Jayakody, Shashika Lokuliyana "Digital Talking Book" [online]: Available: https://www.researchgate.net/publication/281953316_Di gital_Talking_Book 